Article

\title{
High-Yield Di-Rhamnolipid Production by Pseudomonas aeruginosa YM4 and its Potential Application in MEOR
}

\author{
Zhuangzhuang $\mathrm{Li}^{1}$, Yumin Zhang ${ }^{2}$, Junzhang Lin ${ }^{3}$, Weidong Wang ${ }^{3}$ and Shuang $\mathrm{Li}^{1, *}$ \\ 1 College of Biotechnology and Pharmaceutical Engineering, Nanjing Tech University, Nanjing 210009, China; \\ 970344745@njtech.edu.cn \\ 2 College of Food Science and Light Industry, Nanjing Tech University, Nanjing 210009, China; \\ 201861118008@njtech.edu.cn \\ 3 Oil Production Research Institute, Shengli Oil Field Ltd. Co. Sinopec, Dongying 257000, China; \\ linjunzhang.slyt@sinopec.com (J.L.); wangweidong168.slyt@sinopec.com (W.W.) \\ * Correspondence: lishuang@njtech.edu.cn; Tel.: +86-25-58139942; Fax: +86-25-58139942
}

Received: 11 March 2019; Accepted: 9 April 2019; Published: 11 April 2019

\begin{abstract}
Rhamnolipids are a mixture of the homologs species due to variations in the rhamnose units and $\beta$-hydroxy fatty acid moieties, mainly including Rha- $\mathrm{C}_{10}-\mathrm{C}_{10}$, Rha-Rha- $\mathrm{C}_{10}-\mathrm{C}_{10}$, and Rha- $\mathrm{C}_{10}$. In this study, strain P. aeruginosa YM4 was selected for its capacity to efficiently produce di-rhamnolipid (Rha-Rha- $\mathrm{C}_{10}-\mathrm{C}_{10}$ ) as the predominant component with soybean oil and glycerol as carbon source, accounting for $64.8 \%$ and $85.7 \%$ of total products, respectively. The critical micelle concentration (CMC) of rhamnolipid products varies with the content of di-rhamnolipid, whereby lower CMC values corresponding to higher di-rhamnolipid contents. The rhamnolipids containing $85.7 \%$ di-rhamnolipid had the lowest CMC value of $50 \mathrm{mg} / \mathrm{L}$. Accordingly the viscosity-reducing efficiency and oil-washing efficiency of rhamnolipids increased with higher di-rhamnolipid component. At a concentration of $500 \mathrm{mg} / \mathrm{L}$, the rhamnolipids containing 85.7\% di-rhamnolipid worked best and showed $82.5 \%$ oil-washing efficiency, which offered great promise for applications in enhanced oil recovery. The results showed the variation of structure and composition of rhamnolipids had a significant effect on their application.
\end{abstract}

Keywords: rhamnolipid; di-rhamnolipid; biosurfactant; microbial enhanced oil recovery; Pseudomonas aeruginosa

\section{Introduction}

Rhamnolipids, which belong to the broad biomolecule class of glycolipids, are the most intensively studied biosurfactants. As the name implies, rhamnolipids contain a hydrophilic group made up of one or two (1)-rhamnose units and a hydrophobic group consisting of one or two $\beta$-hydroxy fatty acid moieties. Rhamnolipid surfactants were shown to reduce the surface tension of water from 72 to $28 \mathrm{mN} / \mathrm{m}$, and the interfacial tension of water-oil systems from 43 to $<1 \mathrm{mN} / \mathrm{m}$ [1-3]. They display both prominent surface activity and high emulsifying activity, which make them well suited for application in microbial enhanced oil recovery (MEOR). Rhamnolipid-producing microorganisms are used for in situ treatment of oil-containing sands or in ex situ applications [4-6].

Rhamnolipids are primarily produced by Pseudomonas aeruginosa strains. Researchers have long focused on strain improvement and process optimization to acquire high-yielding rhamnolipid producers [7,8]. These rhamnolipids can be mixtures of four to 28 types, mainly including $R$ ha- $\mathrm{C}_{10}-\mathrm{C}_{10}$, Rha-Rha- $\mathrm{C}_{10}-\mathrm{C}_{10}$, and Rha- $\mathrm{C}_{10}$ [9-11]. Among them, di-rhamnolipid exhibits special characteristics, such as a lower critical micelle concentration and better bioavailability [12-15]. 
Although the use of rhamnolipids in enhanced oil recovery has been tested before, until recently, the production of rhamnolipid variants and their efficiency in MEOR have become a research hotspot [16-18]. In this study, the rhamnolipid-producing strain P. aeruginosa YM4 was selected for its capacity to efficiently produce Rha-Rha- $C_{10}-C_{10}$ as the major component with soybean oil and glycerol as carbon source. The rhamnolipid products, homolog composition, and enhanced oil recovery properties, including surfactant activity, emulsifying capability, viscosity-reducing efficiency, and oil-washing efficiency, were tested in this work. The result of rhamnolipid homolog composition and their applicability to MEOR should contribute to the potential use of the rhamnolipid products and optimization of products composition.

\section{Results}

\subsection{Production of Rhamnolipids}

Rhamnolipids were produced by P. aeruginosa YM4 and the parental strain in shake flask using glycerol and soybean oil as carbon sources for $96 \mathrm{~h}$; the titer of rhamnolipid products of the parental strain was $16.7 \mathrm{~g} / \mathrm{L}$ and $17.9 \mathrm{~g} / \mathrm{L}$, respectively; the titer of rhamnolipid products of YM4 was 23.9 and $25.1 \mathrm{~g} / \mathrm{L}$, respectively (Table 1). The rhamnolipids production by YM4 increased by 30\%. Both glycerol and soybean oil could be used as carbon sources to efficiently produce rhamnolipid by YM4 with conversion yield of approximately 80 to $85 \%$.

Table 1. Effects of the carbon source on rhamnolipid production.

\begin{tabular}{cccccc}
\hline \multirow{2}{*}{ Strain } & Carbon Source & Biomass $\left(\mathbf{O D}_{\mathbf{6 0 0}}\right)$ & Productivity $(\mathbf{m g} / \mathbf{L} / \mathbf{h})$ & Titer $(\mathbf{g} / \mathbf{L})$ & Conversion Yield \\
\hline \multirow{2}{*}{ YM4 } & glycerol & $5.1 \pm 0.2$ & $249.0 \pm 12.5$ & $23.9 \pm 1.2$ & $79.7 \pm 4.0 \%$ \\
& soybean oil & $7.0 \pm 0.2$ & $260.9 \pm 14.6$ & $25.1 \pm 1.4$ & $83.5 \pm 4.6 \%$ \\
\hline \multirow{2}{*}{ Parent } & glycerol & $5.8 \pm 0.3$ & $173.9 \pm 24.0$ & $16.7 \pm 2.3$ & $55.7 \pm 7.6 \%$ \\
& soybean oil & $7.4 \pm 0.2$ & $186.4 \pm 16.7$ & $17.9 \pm 1.6$ & $59.7 \pm 5.3 \%$ \\
\hline
\end{tabular}

\subsection{Proportions of Rhamnolipid Variants Produced by P. aeruginosa YM4}

HPLC profiles of the mixture of rhamnolipid variants produced by P. aeruginosa YM4 are shown in Figure 1. The rhamnolipid variants were identified by comparing their retention times and mass spectra with those of commercially available authentic reference standards. The main components appeared as peaks 1 and 2 with molecular masses of 649 (Rha-Rha- $\left.C_{10}-C_{10}\right)$ and $503\left(R h a-C_{10}-C_{10}\right)$, respectively (Figure 2).

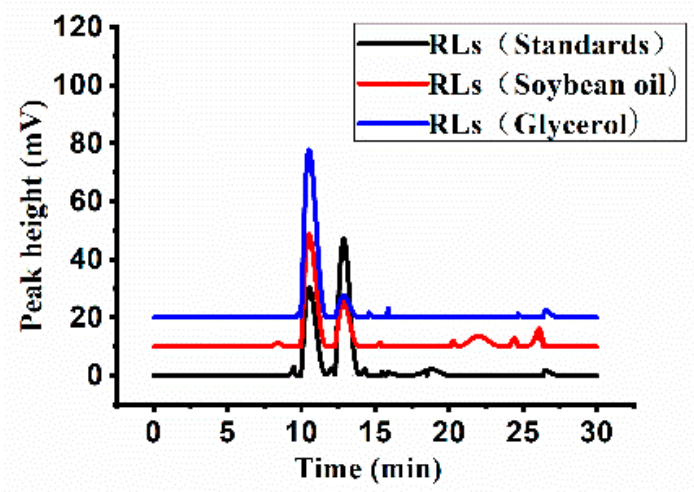

Figure 1. High performance liquid chromatography-evaporative light scattering detector (HPLC-ELSD) profile of rhamnolipids produced by P. aeruginosa YM4. The black line represents the rhamnolipid standard and the red and blue lines represent the rhamnolipids products from soybean oil and glycerol, respectively. 

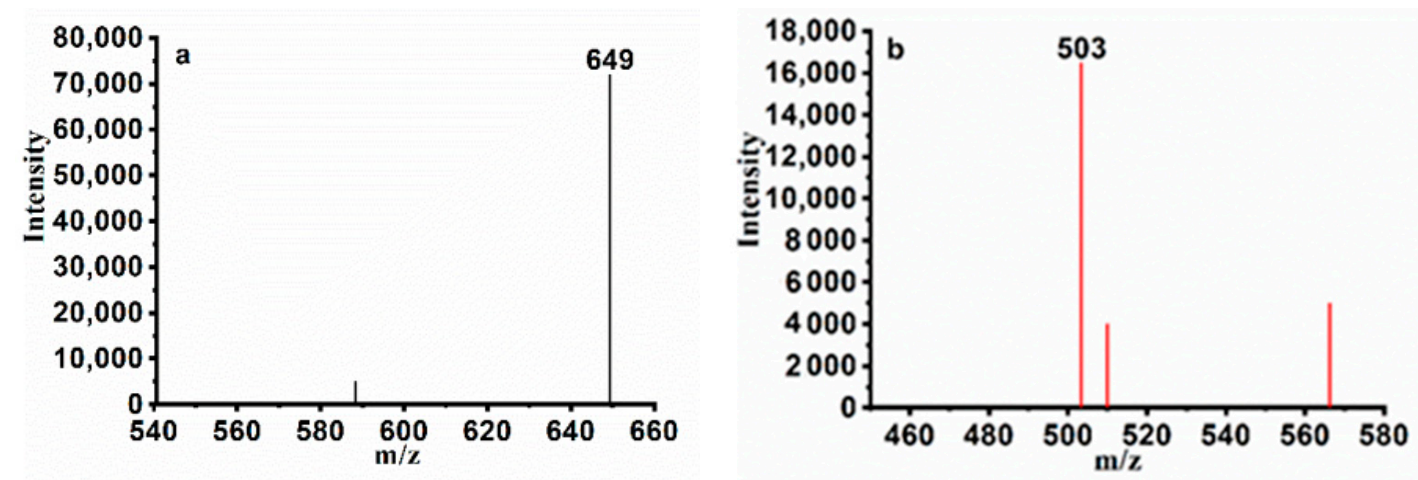

Figure 2. HPLC-MS analysis of the rhamnolipids. LC-MS spectrum of main components (retention times of $10.023 \mathrm{~min}(\mathbf{a})$ and $12.664 \mathrm{~min}(\mathbf{b})$ ) of the rhamnolipids.

The proportions of rhamnolipid products obtained with the two carbon sources were shown in Table 2. Among the rhamnolipid products of the strain YM4, Rha-Rha- $C_{10}-C_{10}$ and Rha- $C_{10}-C_{10}$ were the most abundant, accounting for approximately 90 to $95 \%$ of the total. However, the di-rhamnolipid proportion of the products was significantly affected by the carbon source, varying from 64.8 to $85.7 \%$. When glycerol was used as carbon source, the contents of Rha-Rha- $C_{10}-C_{10}$ reached a maximum of $85.7 \%$, and the ratio of di-rhamnolipids to mono-rhamnolipids was approximately 9:1. However, the mono-rhamnolipid proportion increased significantly with soybean oil as carbon source; and the ratio of di-rhamnolipids to mono-rhamnolipids was approximately 2:1.

Table 2. The components of rhamnolipid products.

\begin{tabular}{|c|c|c|c|c|}
\hline \multirow{2}{*}{ Structure } & \multirow{2}{*}{$\begin{array}{l}\text { Retention Time } \\
\text { (min) }\end{array}$} & \multicolumn{3}{|c|}{ Rhamnolipid Preparations } \\
\hline & & Glycerol & Soybean Oil & Standard \\
\hline Rha-Rha- $\mathrm{C}_{10}-\mathrm{C}_{10}$ & 10.023 & $85.7 \%$ & $64.8 \%$ & $31.8 \%$ \\
\hline Rha- $\mathrm{C}_{10}-\mathrm{C}_{10}$ & 12.664 & $9.3 \%$ & $27.0 \%$ & $64.0 \%$ \\
\hline Rha- $C_{12: 1}$ & 15.416 & $3.0 \%$ & ND & ND \\
\hline Rha- $C_{14: 2}-C_{10}$ & 18.536 & ND & ND & $1.9 \%$ \\
\hline Rha- $\mathrm{C}_{10: 1}$ & 20.157 & ND & $5.2 \%$ & ND \\
\hline Rha- $\mathrm{C}_{10: 1}-\mathrm{C}_{8}$ & 22.117 & ND & $3.0 \%$ & ND \\
\hline Rha- $C_{14: 1}$ & 25.987 & $2.0 \%$ & ND & $2.3 \%$ \\
\hline
\end{tabular}

ND: not detectable.

\subsection{Measurement of the Critical Micelle Concentration (CMC)}

The rhamnolipids were able to reduce the surface tension of water from 72 to $28 \mathrm{mN} / \mathrm{m}$ at room temperature $\left(25^{\circ} \mathrm{C}\right)$. The relationship between the surface tension and the structure of rhamnolipids was analyzed by measuring the surface tension of rhamnolipid mixtures at different concentrations (0-200 $\mathrm{mg} / \mathrm{L}$; Figure 3). The CMC values of the rhamnolipid products from glycerol and soybean oil were 50 and $65 \mathrm{mg} / \mathrm{L}$, respectively. By contrast, the CMC value of the standard sample (di-rhamnolipid accounting for $31.8 \%$ ) was $\sim 110 \mathrm{mg} / \mathrm{L}$. The most significant difference between the rhamnolipid products and the standard sample was the proportion of di-rhamnolipid; the rhamnolipid products containing 85.7 and $64.8 \%$ of di-rhamnolipid, much higher than those in the standard sample $(31.8 \%)$. The results showed the critical micelle concentration (CMC) of rhamnolipids was closely correlated with the composition of rhamnolipid variants, lower CMC values corresponding to higher di-rhamnolipid contents. 


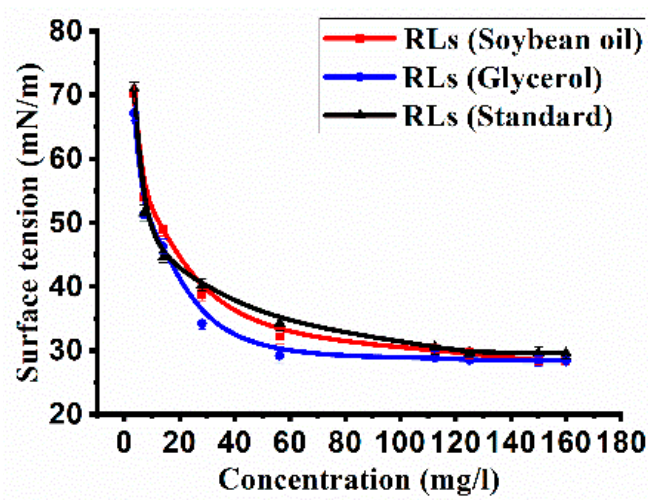

Figure 3. The critical micellar concentration (CMC) determination for rhamnolipids. The CMC was determined by measuring the changes of surface tension with different concentrations of rhamnolipids. The error bars represent standard deviations from three independent experiments $(n=3)$.

\subsection{Emulsification Activity of Rhamnolipid Products}

In addition to surface tension, the stability of oil-in-water emulsions is often used as an indicator of surface activity [19]. The emulsification activity of rhamnolipid products, SDS, TTAB, and Tween 80 are shown in Figure 4. The rhamnolipid products were able to emulsify liquid paraffin, kerosene and n-hexane. Compared with SDS and TTAB, the rhamnolipid products and Tween 80 showed a more stable and efficient emulsification activity at a concentration of $500 \mathrm{mg} / \mathrm{L}$. The emulsifying activity of different components of rhamnolipid products did not differ significantly.

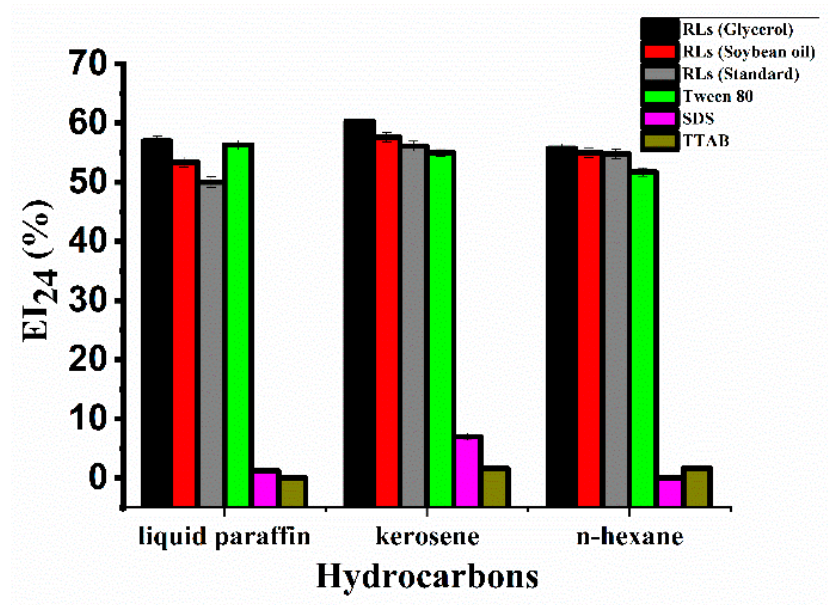

Figure 4. The emulsification index at $24 \mathrm{~h}\left(\mathrm{EI}_{24}\right)$ of surfactants in the different hydrocarbons. To measure $\mathrm{EI}_{24}, 5 \mathrm{~mL}$ of surfactant solution was added to $5 \mathrm{~mL}$ of hydrocarbons in a glass test tube; the mixture was vortexed at high speed for $2 \mathrm{~min}$, and incubated at room temperature for $24 \mathrm{~h}$. The concentration of all surfactants was $500 \mathrm{mg} / \mathrm{L}$. The error bars represent standard deviations from three independent experiments $(n=3)$.

\subsection{Viscosity-Reducing Efficiency of Rhamnolipid Products}

Four crude oil samples were used to access the viscosity-reducing efficiency of rhamnolipid products at the same concentration. The results were shown in Table 3. The rhamnolipids $(G)$ containing $85.7 \%$ di-rhamnolipid had a better viscosity-reducing effects than rhamnolipids (S) containing $64.8 \%$ di-rhamnolipid. This indicated that higher di-rhamnolipid content had better viscosity-reducing activity. 
Table 3. Viscosity-reducing effect of rhamnolipid products.

\begin{tabular}{cccc}
\hline \multirow{2}{*}{ Crude Oil } & \multirow{2}{*}{ Viscosity (mPas) } & \multicolumn{2}{c}{ Viscosity-Reducing (2h/Overnight) } \\
\cline { 3 - 4 } & & RLs (G) $^{\mathbf{a}}$ & RLs (S) $^{\mathbf{b}}$ \\
\hline CQ63 & 585 & $95.7 \% / 91.5 \%$ & $79.4 \% / 76.3 \%$ \\
33 & 3654 & $99.2 \% / 14.5 \%$ & $89.2 \% / 7.7 \%$ \\
$68-73$ & 7948 & $96.2 \% / 18.4 \%$ & $84.6 \% / 15.2 \%$ \\
ZEN & 14187 & $99.9 \% / 32.6 \%$ & $99.1 \% / 19.9 \%$
\end{tabular}

Thirty grams of rhamnolipid solution $(5 \mathrm{~g} / \mathrm{L})$ was added to $70 \mathrm{~g}$ of crude oil, incubated at $50{ }^{\circ} \mathrm{C}$ for $2 \mathrm{~h}$, and then stirred evenly to determine the viscosity of mixture. After staying still at room temperature overnight, the viscosity of mixture was determined again. Each batch of experiment was repeated 3 times. ${ }^{a}$ RLs (G) means rhamnolipids products from glycerol; ${ }^{\mathrm{b}}$ RLs (S) means rhamnolipids products from soybean oil.

\subsection{Oil-Washing Efficiency of Rhamnolipid Products}

The performance of rhamnolipids products, rhamnolipid standards, as well as SDS and Tween 80 on oil-washing was studied using artificial oil sand. The results were shown in Table 4 . At the concentration of $1000 \mathrm{mg} / \mathrm{L}$, rhamnolipid (G) and Tween 80 removed more than $99 \%$ of oil from the oil sand, followed by rhamnolipid (soybean oil), which removed $87.5 \%$ of the oil. However, the rhamnolipid standard removed $51.7 \%$ of the oil, much less than the rhamnolipid products. At the concentration of $500 \mathrm{mg} / \mathrm{L}$, rhamnolipid (glycerol) worked best: it could still remove more than $80 \%$ of the oil. The results suggested the components of rhamnolipids had a great influence on oil-washing efficiency, with a higher di-rhamnolipid content increasing the oil-washing efficiency. Although the chemical surfactant Tween 80 exhibited excellent oil-washing efficiency, it should be noted that the removed oil particles easily adhered to the wall of the flask (Figure 5). By contrast, the oil particles removed by the rhamnolipid products were homogeneously dispersed, which greatly simplifies the subsequent treatment.

Table 4. Oil-washing efficiency of surfactant solutions.

\begin{tabular}{ccc}
\hline Surfactant & Concentration $(\mathbf{m g} / \mathrm{L})$ & \% of Oil Removed \\
\hline RLs (Glycerol) & 1000 & $99.3 \pm 0.3$ \\
85.7\% di-rhamnolipids & 500 & $82.5 \pm 1.1$ \\
\hline RLs (Soybean oil) & 1000 & $87.5 \pm 2.0$ \\
64.8\% di-rhamnolipids & 500 & $53.7 \pm 1.7$ \\
\hline RLs (Standard) & 1000 & $57.1 \pm 1.4$ \\
$31.8 \%$ di-rhamnolipids & 500 & $28.8 \pm 2.2$ \\
\hline \multirow{2}{*}{ SDS } & 1000 & $38.7 \pm 0.9$ \\
& 500 & $25.0 \pm 1.3$ \\
\hline \multirow{2}{*}{ Tween 80} & 1000 & $99.6 \pm 0.1$ \\
Water & 500 & $87.2 \pm 1.5$ \\
\hline
\end{tabular}

A sample comprising $2 \mathrm{~g}$ of artificial oil sand was added to $20 \mathrm{~mL}$ of surfactant solutions in $50 \mathrm{~mL}$ flasks, and then shaken at $90 \mathrm{rpm}$ and $70^{\circ} \mathrm{C}$ for $24 \mathrm{~h}$. The error bars represent standard deviations from three independent experiments. 


\section{A $1000 \mathrm{mg} / \mathrm{L}$}

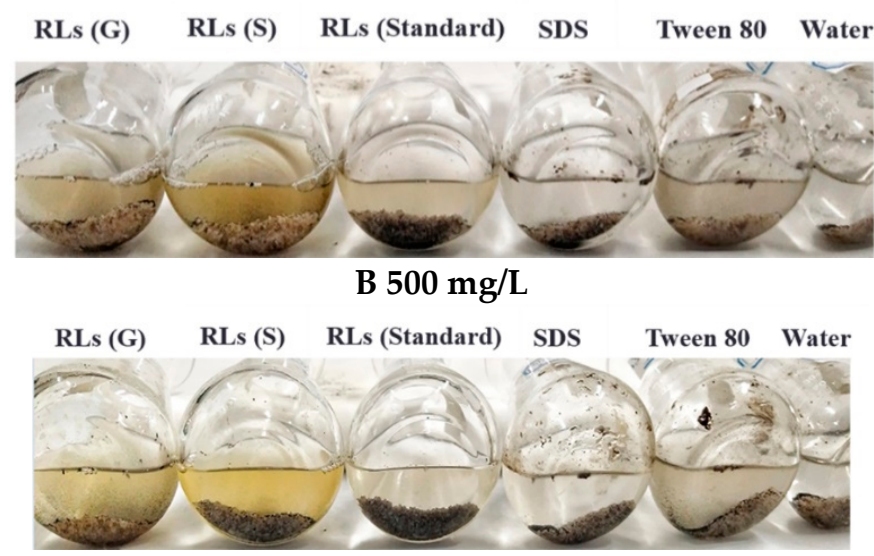

Figure 5. Bottom view of the oil sands after oil-washing by surfactants. The oil sands were treated with the surfactant solutions for $24 \mathrm{~h}$ at $70{ }^{\circ} \mathrm{C}$ and $90 \mathrm{rpm}$ (A,B). RLs (glycerol) refer to the rhamnolipid products from glycerol; RLs (Soybean oil) refer to the rhamnolipid products from soybean oil. RLs (G) means rhamnolipids products from glycerol; RLs (S) means rhamnolipids products from soybean oil.

\section{Discussion}

Rhamnolipids are mainly known to be produced by Pseudomonas aeruginosa during cultivation on specific substrates, the most commonly used being plant oils, sugars, and glycerol. Many studies have demonstrated that the fermentation conditions and carbon sources can dramatically affect the yield and composition of rhamnolipids.

Carbon sources can affect the supply of precursors for rhamnolipid biosynthesis, thus P. aeruginosa strains are able to produce various rhamnolipid variants, which may differ in the chain length of the fatty acids or in the rhamnose units, when growing on different substrates [20]. While growing on glycerol and soybean oil, the ratios of Rha-Rha- $C_{10}-C_{10} /$ Rha- $-C_{10}-C_{10}$ in the products of Pseudomonas aeruginosa J16 were 4.2 and 2.3, respectively. After optimizing medium components for enhanced di-rhamnolipid production, the di-rhamnolipid accounted for $75 \pm 5 \%$ of total rhamnolipid. However, the maximum concentration and volumetric productivity for di-rhamnolipid was $3.19 \mathrm{~g} / \mathrm{L}$ and $44 \mathrm{mg} /(\mathrm{L} . \mathrm{h})$, respectively; the product concentration and volumetric productivity were relatively low and not suitable for industrial applications [21].

The biosynthesis of rhamnolipids needs two precursors-dTDP-L-rhamnose and beta-hydroxy fatty acids. The synthesis of Rha- $C_{10}-C_{10}$ is catalyzed by rhamnosyltransferase I (encoded by rhlAB) combining dTDP-L-rhamnose and $\beta$-hydroxydecanoyl- $\beta$-hydroxydecanoate, while Rha-Rha- $C_{10}-C_{10}$ is synthesized from Rha- $\mathrm{C}_{10}-\mathrm{C}_{10}$ and dTDP-L-rhamnose with the aid of rhamnosyltransferase II (encoded by $\mathrm{rhlC}$ ). Tiso et al. designed and constructed a recombinant Pseudomonas putida KT2440 to specifically produce different biosurfactant mixtures via the tailored expression of rhamnolipid synthesis genes from P. aeruginosa PA01 in recombinant Pseudomonas putida cell factories [18]. First, the recombinant Pseudomonas putida could produce a mixture of different mono-rhamnolipid congeners, and then, after transforming the rhlC containing vector, the new recombinant was able to produce di-rhamnolipids. Of the total biosurfactants, $86 \%$ were di-rhamnolipids and $13 \%$ were mono-rhamnolipids. This was the first report of efficient di-rhamnolipids production in recombinant bacterium. It should be noted the function genes donor P. aeruginosa PA01 also produced mainly the Rha-Rha- $C_{10}-C_{10}$ congener; The molar ratio of di-rhamnolipid to mono-rhamnolipid in the products of P. aeruginosa PA01 with sunflower oil was approximately 2:1 [22].

In this study, the rhamnolipid yields were not significantly affected by the type of carbon source; both glycerol and soybean oil could be efficiently used by the YM4 strain with conversion yields of $80-85 \%$ (Table 2). However, the composition of rhamnolipids differed significantly, and the di-rhamnolipid proportion varied from 64.8 to $85.7 \%$. These yields and proportions make 
Pseudomonas aeruginosa YM4 an unusually efficient di-rhamnolipid (Rha-Rha- $\mathrm{C}_{10}-\mathrm{C}_{10}$ ) producer. Especially when using glycerol as carbon source, the rhamnolipid products contained a di-rhamnolipid proportion as high as $85.7 \%$. Hanser et al. showed that the rhamnosyl moiety of rhamnolipids can be directly condensed from two glycerol molecules that are not rearranged in their carbon chains, and the fatty acid chain portion can also be obtained by a fatty acid synthesis route from glycerol [23]. Therefore, glycerol has a metabolic advantage for the glycosylation of the rhamnolipid and the synthesis of the lipid-based moiety. This may also be the reason why YM4 utilizes glycerol to produce di-rhamnolipids at a higher yield. A comparison of the reported rhamnolipid variants produced by different strains is shown in Table 5. To the best of our knowledge, this is the highest yield of di-rhamnolipid produced by Pseudomonas species.

Table 5. The rhamnolipid products and di-rhamnolipid contents from various strains.

\begin{tabular}{|c|c|c|c|c|c|}
\hline Strain & Carbon Source & $\begin{array}{l}\text { Conversion } \\
\text { Yield (\%) }\end{array}$ & $\begin{array}{c}\text { Content of } \\
\text { Di-Rhamnolipid (\%) }\end{array}$ & $\begin{array}{l}\text { Surface Tension } \\
(\mathrm{mN} / \mathrm{m})\end{array}$ & Reference \\
\hline P. aeruginosa $\mathrm{J} 16$ & Glycerol & 9 & 75 & NA & [21] \\
\hline P. aeruginosa TIB-R02 & Palm oil & 80 & 60 & NA & {$[24]$} \\
\hline P. aeruginosa 57RP & Mannitol & NA & $\sim 55-60$ & NA & {$[20]$} \\
\hline Recombinant P. putida & Glucose & 33 & 86 & NA & [18] \\
\hline P. aeruginosa L2-1 & Waste oil & NA & $\sim 70-75$ & 30 & [25] \\
\hline P. aeruginosa MR01 & $\begin{array}{l}\text { Soybean oil } \\
\text { Glucose }\end{array}$ & $\begin{array}{c}\text { NA } \\
24\end{array}$ & $\begin{array}{l}42.7 \\
77.2\end{array}$ & $\begin{array}{l}29.9 \\
\text { NA }\end{array}$ & $\begin{array}{c}{[3]} \\
{[26]}\end{array}$ \\
\hline P. aeruginosa $\mathrm{E} 03-40$ & $\begin{array}{c}\text { Glycerol } \\
\text { Soybean oil }\end{array}$ & $\begin{array}{l}10 \\
47\end{array}$ & $\begin{array}{l}64 \\
18\end{array}$ & $\begin{array}{l}\text { NA } \\
\text { NA }\end{array}$ & {$[27]$} \\
\hline P. aeruginosa $\mathrm{YM} 4$ & $\begin{array}{c}\text { Glycerol } \\
\text { Soybean oil }\end{array}$ & $\begin{array}{l}79.7 \\
83.5\end{array}$ & $\begin{array}{l}85.7 \\
64.8\end{array}$ & $\begin{array}{l}29.2 \\
32.2\end{array}$ & This study \\
\hline
\end{tabular}

NA: not available.

Rhamnolipid congeners with variable numbers of hydrophobic/hydrophilic residues and their mixtures feature different physicochemical properties that might lead to diverse applications. The composition and distribution of homologs greatly affect the surface activity characteristics of rhamnolipid preparations. Marcia et al. pointed out that rhamnolipids with longer fatty acid chains had stronger hydrophobicity, but they were more hydrophilic if the sugar component was di-rhamnose [28]. Therefore, the variation of structure and composition can affect the surface activity and stability of rhamnolipids in the aqueous phase [21]. The critical micelle concentration (CMC) of rhamnolipid is also affected by the length of the fatty acid chain and the number of rhamnose units. If the rhamnolipid structure contains two rhamnoses, a longer fatty acid chain leads to a lower CMC [12,20]. Lang et al. reported that the di-rhamnolipid Rha-Rha- $\mathrm{C}_{10}-\mathrm{C}_{10}$ has a CMC of $5 \mathrm{mg} / \mathrm{L}$, which is much lower than that of Rha- $C_{10}-C_{10}$, which has a value of $40 \mathrm{mg} / \mathrm{L}$ [29]. Among the rhamnolipid products of the YM4 strain, the main congeners were Rha-Rha- $C_{10}-C_{10}$ and Rha- $C_{10}-C_{10}$, accounting for approximately $90-95 \%$ of the total. Rhamnolipid products with a higher percentage of di-rhamnolipid (Rha-Rha- $\mathrm{C}_{10}-\mathrm{C}_{10}$ ) had lower $\mathrm{CMC}$ values, and both of the products showed much lower CMC values than the commercially available rhamnolipid standards (Figure 3). Gong et al. studied the influence of different congeners of rhamnolipids on interfacial tension (IFT), and found that a high percentage of di-rhamnolipid (Rha-Rha- $\mathrm{C}_{10}-\mathrm{C}_{10}$ ) facilitates a decrease of the IFT [24]. Considering the lower CMC value and IFT of di-rhamnolipid, it is easy to explain the better oil-washing efficiency and viscosity reduction that was observed in the rhamnolipid product containing $85.7 \%$ of di-rhamnolipid. The present results suggest the di-rhamnolipids would be the better choice in the MEOR application.

To be competitive with chemical surfactants, many works focused on enhancing rhamnolipid titers and yields by selecting suitable substrates and optimizing the fermentation process. However, the contents of biosurfactant isoforms or congers also have a significant effect on their application. The lower CMC values and better oil-washing efficiency of di-rhamnolipid observed in this study 
indicates that the proportion of di-rhamnolipid should be paid special attention in rhamnolipids production for MEOR applications.

\section{Materials and Methods}

\subsection{Bacterial Strain and Culture Conditions}

P. aeruginosa YM4 (CCTCC No.: M2017494), was originally isolated from crude oil contaminated soil samples and obtained via random mutagenesis with atmospheric room temperature plasma (ARTP). The strain was cultured in Luria-Bertani (LB) medium $(10 \mathrm{~g} / \mathrm{L}$ peptone, $5 \mathrm{~g} / \mathrm{L}$ yeast extract, $10 \mathrm{~g} / \mathrm{L} \mathrm{NaCl}$ ) at $200 \mathrm{rpm}$ and $37^{\circ} \mathrm{C}$ for $12 \mathrm{~h}$. The optic density of seed culture was about 2.0-2.5, and it was then transferred into the $250 \mathrm{~mL}$ flask containing $50 \mathrm{~mL}$ fermentation medium at a $3 \%(v / v)$ inoculation rate. The fermentation for rhamnolipid production was continued at $37^{\circ} \mathrm{C}$ and $200 \mathrm{rpm}$ for $96 \mathrm{~h}$. The optimal fermentation medium comprised $(\mathrm{g} / \mathrm{L}) \mathrm{K}_{2} \mathrm{HPO} 4 \cdot 3 \mathrm{H}_{2} \mathrm{O}(4), \mathrm{KH}_{2} \mathrm{PO}_{4}(4), \mathrm{MgSO}_{4} \cdot 7 \mathrm{H}_{2} \mathrm{O}$ $(0.2), \mathrm{CaCl}_{2}(0.1)$, yeast extract (1), trace elements solution $(2.5 \mathrm{~mL} / \mathrm{L})$, and carbon and nitrogen sources comprising glycerol (30), $\mathrm{NaNO}_{3}$ (12), soybean oil (30), or $\mathrm{NaNO}_{3}$ (8), respectively. The trace elements solution contained (g/L) $\mathrm{FeCl}_{3}(0.16), \mathrm{CuSO}_{4}(0.15), \mathrm{ZnSO}_{4} \cdot 7 \mathrm{H}_{2} \mathrm{O}$ (1.5), and $\mathrm{MnSO}_{4} \cdot \mathrm{H}_{2} \mathrm{O}$ (1.5).

\subsection{Extraction and Purification of Rhamnolipids}

Cells were separated from $100 \mathrm{~mL}$ of fermentation broth by centrifugation $(10,956 \times \mathrm{g}, 15 \mathrm{~min}$, $20^{\circ} \mathrm{C}$, Hitachi CR21GIII, Tokyo, Japan). The supernatant was subjected to acid precipitation by the addition of $10 \mathrm{M} \mathrm{HCl}$ to give a final $\mathrm{pH}$ of 2.0 and the precipitate was formed overnight at $4{ }^{\circ} \mathrm{C}$. The precipitate was harvested by centrifugation $\left(10,956 \times g, 15 \mathrm{~min}, 4^{\circ} \mathrm{C}\right)$ and extracted with $300 \mathrm{~mL}$ ethyl acetate. The organic phase was collected, and the solvent was removed in a rotary evaporator (Hei-VAP Industrial, Berlin, Germany) leaving a brown paste. The paste was re-extracted with $300 \mathrm{~mL}$ ethyl acetate, and the supernatant was collected by centrifugation $\left(10,956 \times g, 15 \mathrm{~min}, 4{ }^{\circ} \mathrm{C}\right)$. Finally, the crude rhamnolipids were obtained by rotary evaporation.

\subsection{HPLC-ELSD Analysis}

Rhamnolipids were detected directly, without derivatization, by HPLC using an Evaporative Light Scattering Detector (ELSD), as described previously [30].

After the end of the fermentation, $0.1 \mathrm{~mL}$ of the cell-free supernatant was mixed with $1.9 \mathrm{~mL}$ of absolute ethanol and shaken for $1 \mathrm{~min}$, and then separated by centrifugation $(10,956 \times g, 5 \mathrm{~min}$, $4{ }^{\circ} \mathrm{C}$ ). The supernatant was analyzed using a 1260 Infinity HPLC-ELSD (Agilent Technologies, Palo Alto, CA, USA) equipped with a C18 column $(4.6 \times 150 \mathrm{~mm}, 5 \mu \mathrm{m}$; Sepax Technologies, Inc, Suzhou, China). The ELSD was set up with a drift temperature of $60^{\circ} \mathrm{C}$ and a nebulizer flow rate of $1.5 \mathrm{~L} / \mathrm{min}$. The mobile phase A (acetonitrile) and mobile phase B (water with $0.05 \%$ formic acid) were used in a linear gradient from $30 \%$ to $100 \%$ of acetonitrile in $40 \mathrm{~min}$. Standard curves comprising 0.1 to $1 \mathrm{mg} / \mathrm{mL}$ of rhamnolipids (AGA102317b; AGAE Technologies, Corvallis, OR, USA) were used for quantification.

\subsection{HPLC-MS Analysis}

Sample pretreatment was the same as Section 4.3. For quadrupole-time of flight (Q-TOF) analysis, the analytes were separated as described above, and mass spectrometry was conducted as follows; the nebulized gas and dry gas were $\mathrm{N}_{2}$, the ESI source was used in the high performance liquid chromatography-quadrupole-time of flight-mass spectrometry (HPLC/Q-TOF-MS) system: ion source temperature was $350{ }^{\circ} \mathrm{C}$, ion source gas flow rate was $10 \mathrm{~L} / \mathrm{min}$, spray voltage was $45 \mathrm{P}$, and the mass spectrum scanning range was 200 to $1000 \mathrm{~m} / \mathrm{z}$.

\subsection{Determination of the Critical Micelle Concentration (CMC) of Rhamnolipids}

The critical micelle concentration (CMC) was determined by measuring the surface tension curve of the separated biosurfactant dilution as described before [31]. The changes in surface 
tension of rhamnolipid solutions with different concentrations (0-200 mg/L) were measured using an automated tensiometer (BZY-3B, Shanghai Automation Instrumentation Sales Center, Shanghai, China) at room temperature.

\subsection{Determination of the Emulsification Index $\left(E I_{24}\right)$}

The emulsification index $\left(\mathrm{EI}_{24}\right)$ was measured using the method described by Cooper and Goldenberg [32]. Briefly, $5 \mathrm{~mL}$ solutions of different chemical surfactants (Sodium dodecyl sulfate (SDS), Tetradecyl trimethyl ammonium Bromide (TTAB), Tween 80) and rhamnolipid products, and $5 \mathrm{~mL}$ of different hydrocarbons (n-hexane, liquid paraffin, kerosene) were mixed in $10 \mathrm{~mL}$ stoppered glass test tubes, in different combinations. The mixtures were vortexed at high speed ( 10,000 rpm) for $2 \mathrm{~min}$, and subsequently kept without agitation at room temperature for $24 \mathrm{~h}$. The $\mathrm{EI}_{24}$ was calculated by dividing the measured emulsion layer height by the total height of the mixture and multiplying by 100 .

\subsection{Assessment of the Viscosity-Reducing Effect of Rhamnolipids on Crude Oil}

To investigate the effect of rhamnolipids on the viscosity crude oil, $30 \mathrm{~g}$ of rhamnolipids solution $(5 \mathrm{~g} / \mathrm{L})$ and $70 \mathrm{~g}$ of crude oil were mixed in a glass beaker, and viscosity of the mixtures was measured immediately after heating at $50{ }^{\circ} \mathrm{C}$ for $2 \mathrm{~h}$ using viscometer (Shanghai Biaozhuo Scientific Instrument Co., Ltd., Shanghai, China). Then, the mixtures were kept at room temperature overnight and the viscosity was measured again. The crude oil samples used in the experiment were supplied by the Shengli Oilfield Microbial Oil Recovery Research Institute, Dongying, China.

\subsection{Assessment of the Oil-Washing Efficiency of Rhamnolipids on Oil Sands}

Standard oil sand for measuring the oil washing efficiency was obtained by mixing $170 \mathrm{~g}$ of quartz sand (Shengli Oilfield, China), $4 \mathrm{~g}$ of man-made crude oil (83\% crude oil, 12\% petroleum asphalt, 5\% paraffin (m/m); Shengli Oilfield, Dongying, China), and $10 \mathrm{~mL}$ petroleum ether (China Pharmaceutical Chemical Reagent Co., Ltd., Beijing, China) with stirring and heating at $80{ }^{\circ} \mathrm{C}$ for $1 \mathrm{~h}$, and then evaporating the petroleum ether at $80-90^{\circ} \mathrm{C}$. Sequel samples containing $20 \mathrm{~mL}$ of surfactant solution were added to each flask containing $2 \mathrm{~g}$ of the thus-formed oil sand. The flask was then shaken at $90 \mathrm{rpm}$ and $70{ }^{\circ} \mathrm{C}$ for $24 \mathrm{~h}$. The oil removed from the solution was transferred to a new container, and the remaining detergent solution was rinsed in a flask with distilled water until the eluent was clear. The washed flask with oil sand was then placed into the oven and dried at $60{ }^{\circ} \mathrm{C}$ for $12 \mathrm{~h}$, cooled to room temperature in a desiccator, and the dry weight of the oil sand measured. The oil-washing efficiency was calculated using the formula:

$$
X=\frac{W 0-W 1}{W 0 * k} \times 100 \%
$$

$X$-Oil-washing efficiency, \%;

W0-Added oil sands quality, g;

W1-Dried oil sands quality, g;

$k$-The proportion of oil in oil sands, $\%$.

\section{Conclusions}

Strain P. aeruginosa YM4 was able to efficiently produce di-rhamnolipid ( $R$ ha- $R$ ha- $\mathrm{C}_{10}-\mathrm{C}_{10}$ ) as the predominant component with soybean oil and glycerol as carbon source, accounting for $64.8 \%$ and $85.7 \%$ of total products, respectively. The results of enhanced oil recovery properties, including surfactant activity, emulsifying capability, viscosity-reducing efficiency, and oil-washing efficiency, of the two types of rhamnolipid products indicated the proportion of di-rhamnolipid in rhamnolipids production was one of the key factors for MEOR applications. 
Author Contributions: Data Curation, Z.L. and Y.Z.; Investigation, Z.L. and Y.Z.; Writing一Original Draft, Z.L.; Writing-Review \& Editing, S.L., W.W. and J.L.

Funding: This research was funded by the National Natural Science Foundation of China, grant number 51774188.

Acknowledgments: This work was supported by the National Natural Science Foundation of China (No. 51774188) and the Jiangsu Synergetic Innovation Center for Advanced Bio-Manufacture.

Conflicts of Interest: The authors declare no conflict of interest.

\section{References}

1. Henkel, M.; Muller, M.M.; Kugler, J.H.; Lovaglio, R.B.; Contiero, J.; Syldatk, C.; Hausmann, R. Rhamnolipids as biosurfactants from renewable resources: Concepts for next-generation rhamnolipid production. Process Biochem. 2012, 47, 1207-1219. [CrossRef]

2. Patel, R.M.; Desai, A.J. Surface-active properties of rhamnolipids from Pseudomonas aeruginosa GS3. J. Basic Microbiol. 1997, 37, 281-286. [CrossRef]

3. Lotfabad, T.B.; Ebadipour, N.; Roostaazad, R.; Partovi, M.; Bahmaei, M. Two schemes for production of biosurfactant from Pseudomonas aeruginosa MR01: Applying residues from soybean oil industry and silica sol-gel immobilized cells. Colloids Surf. B Biointerfaces 2017, 152, 159-168. [CrossRef] [PubMed]

4. Gao, C.H. Experiences of microbial enhanced oil recovery in Chinese oil fields. J. Pet. Sci. Eng. 2018, 166, 55-62. [CrossRef]

5. Van Hamme, J.D.; Singh, A.; Ward, O.P. Recent advances in petroleum microbiology. Microbiol. Mol. Biol. Rev. 2003, 67, 503-549. [CrossRef] [PubMed]

6. Sen, R. Biotechnology in petroleum recovery: The microbial EOR. Prog. Energy Combust. Sci. 2008, 34, 714-724. [CrossRef]

7. Syldatk, C.; Lang, S.; Wagner, F.; Wray, V.; Witte, L. Chemical and Physical Characterization of 4 Interfacial-Active Rhamnolipids from Pseudomonas Spec Dsm 2874 Grown on Normal-Alkanes. Z. Nat. C-A J. Biosci. 1985, 40, 51-60.

8. Parra, J.L.; Guinea, J.; Manresa, M.A.; Robert, M.; Mercade, M.E.; Comelles, F.; Bosch, M.P. Chemical characterization and physicochemical behavior of biosurfactants. J. Am. Oil Chem. Soc. 1989, 66, 141-145. [CrossRef]

9. Deziel, E.; Lepine, F.; Milot, S.; Villemur, R. Mass spectrometry monitoring of rhamnolipids from a growing culture of Pseudomonas aeruginosa strain 57RP. Biochim. Biophys. Acta-Mol. Cell Biol. Lipids 2000, 1485, 145-152. [CrossRef]

10. Mulligan, C.N. Environmental applications for biosurfactants. Environ. Pollut. 2005, 133, 183-198. [CrossRef] [PubMed]

11. Monteiro, S.A.; Sassaki, G.L.; de Souza, L.M.; Meira, J.A.; de Araujo, J.M.; Mitchell, D.A.; Ramos, L.P.; Krieger, N. Molecular and structural characterization of the biosurfactant produced by Pseudomonas aeruginosa DAUPE 614. Chem. Phys. Lipids 2007, 147, 1-13. [CrossRef] [PubMed]

12. Mata-Sandoval, J.C.; Karns, J.; Torrents, A. High-performance liquid chromatography method for the characterization of rhamnolipid mixtures produced by Pseudomonas aeruginosa UG2 on corn oil. J. Chromatogr. A 1999, 864, 211-220. [CrossRef]

13. Zhang, Y.M.; Maier, W.J.; Miller, R.M. Effect of rhamnolipids on the dissolution, bioavailability and biodegradation of phenanthrene. Environ. Sci. Technol. 1997, 31, 2211-2217. [CrossRef]

14. Mcclure, C.D.; Schiller, N.L. Effects of Pseudomonas-Aeruginosa Rhamnolipids on Human Monocyte-Derived Macrophages. J. Leukoc. Biol. 1992, 51, 97-102. [CrossRef]

15. McClure, C.D.; Schiller, N.L. Inhibition of macrophage phagocytosis by Pseudomonas aeruginosa rhamnolipids in vitro and in vivo. Curr. Microbiol. 1996, 33, 109-117. [CrossRef]

16. Zhao, F.; Jiang, H.; Sun, H.; Liu, C.; Han, S.; Zhang, Y. Production of rhamnolipids with different proportions of mono-rhamnolipids using crude glycerol and a comparison of their application potential for oil recovery from oily sludge. RSC Adv. 2019, 9, 2885-2891. [CrossRef]

17. Wittgens, A.; Rosenau, F. On the road towards tailor-made rhamnolipids: Current state and perspectives. Appl. Microbiol. Biot. 2018, 102, 8175-8185. [CrossRef] 
18. Tiso, T.; Zauter, R.; Tulke, H.; Leuchtle, B.; Li, W.J.; Behrens, B.; Wittgens, A.; Rosenau, F.; Hayen, H.; Blank, L.M. Designer rhamnolipids by reduction of congener diversity: Production and characterization. Microb. Cell Fact. 2017, 16, 225. [CrossRef]

19. Youssef, N.H.; Duncan, K.E.; Nagle, D.P.; Savage, K.N.; Knapp, R.M.; McInerney, M.J. Comparison of methods to detect biosurfactant production by diverse microorganisms. J. Microbiol. Methods 2004, 56, 339-347. [CrossRef]

20. Déziel, E.; Lépine, F.; Dennie, D.; Boismenu, D.; Mamer, O.A.; Villemur, R. Liquid chromatography/mass spectrometry analysis of mixtures of rhamnolipids produced by Pseudomonas aeruginosa strain 57RP grown on mannitol or naphthalene. Biochim. Biophys. Acta (BBA)-Mol. Cell Biol. Lipids 1999, 1440, $244-252$.

21. Wei, Y.-H.; Cheng, C.-L.; Chien, C.-C.; Wan, H.-M. Enhanced di-rhamnolipid production with an indigenous isolate Pseudomonas aeruginosa J16. Process Biochem. 2008, 43, 769-774. [CrossRef]

22. Muller, M.M.; Hormann, B.; Syldatk, C.; Hausmann, R. Pseudomonas aeruginosa PAO1 as a model for rhamnolipid production in bioreactor systems. Appl. Microbiol. Biot. 2010, 87, 167-174. [CrossRef]

23. Hauser, G.; Karnovsky, M.L. Rhamnose and rhamnolipide biosynthesis by Pseudomonas aeruginosa. J. Biol. Chem. 1957, 224, 91-105.

24. Gong, Z.; Peng, Y.; Wang, Q. Rhamnolipid production, characterization and fermentation scale-up by Pseudomonas aeruginosa with plant oils. Biotechnol. Lett. 2015, 37, 2033-2038. [CrossRef]

25. Costa, S.G.; Nitschke, M.; Lépine, F.; Déziel, E.; Contiero, J. Structure, properties and applications of rhamnolipids produced by Pseudomonas aeruginosa L2-1 from cassava wastewater. Process Biochem. 2010, 45, 1511-1516. [CrossRef]

26. Lotfabad, T.B.; Abassi, H.; Ahmadkhaniha, R.; Roostaazad, R.; Masoomi, F.; Zahiri, H.S.; Ahmadian, G.; Vali, H.; Noghabi, K.A. Structural characterization of a rhamnolipid-type biosurfactant produced by Pseudomonas aeruginosa MR01: Enhancement of di-rhamnolipid proportion using gamma irradiation. Colloids Surf. B Biointerfaces 2010, 81, 397-405. [CrossRef]

27. Sodagari, M.; Invally, K.; Ju, L.K. Maximize rhamnolipid production with low foaming and high yield. Enzym. Microb. Technol. 2018, 110, 79-86. [CrossRef]

28. Nitschke, M.; Costa, S.G.; Contiero, J. Rhamnolipid surfactants: An update on the general aspects of these remarkable biomolecules. Biotechnol. Prog. 2005, 21, 1593-1600. [CrossRef]

29. Surfactants, I.B.; Glycolipids, A.; Surfactants, V.Y.; Surfactants, V.F. Structure and Properties of Biosurf actants. Biosurfactants Biotechnol. 1987, 25, 21.

30. Smyth, T.J.P.; Rudden, M.; Tsaousi, K.; Marchant, R.; Banat, I.M. Protocols for the Detection and Chemical Characterisation of Microbial Glycolipids. In Hydrocarbon and Lipid Microbiology Protocols: Biochemical Methods; McGenity, T.J., Timmis, K.N., Nogales, B., Eds.; Springer: Berlin/Heidelberg, Germany, 2016; pp. $29-60$.

31. Silva, S.; Farias, C.; Rufino, R.; Luna, J.; Sarubbo, L. Glycerol as substrate for the production of biosurfactant by Pseudomonas aeruginosa UCP0992. Colloids Surf. B Biointerfaces 2010, 79, 174-183. [CrossRef]

32. Cooper, D.G.; Goldenberg, B.G. Surface-active agents from two Bacillus species. Appl. Environ. Microbiol. $1987,53,224-229$.

Sample Availability: Samples of the compounds are available from the authors.

(C) 2019 by the authors. Licensee MDPI, Basel, Switzerland. This article is an open access article distributed under the terms and conditions of the Creative Commons Attribution (CC BY) license (http://creativecommons.org/licenses/by/4.0/). 